\title{
Sequenciamento NGS: Status e Perspectivas
}

\author{
By Anderson Freitas
}

12 de junho de 2021

\section{Sequenciamento NGS: Status e Perspectivas}

Anderson Santos de Freitas (D, Helber Barboza Pinto (D)

Revisão: Filipe Zimmer (D), Diego Mariano (D)

BIOINFO - Revista Brasileira de Bioinformática. Edição \#01. Julho, 2021

DOI: $10.51780 / 978-6-599-275326-04$

ext Generation Sequencing (NGS), ou Sequenciamento de nova Geração são o conjunto de técnicas de Biologia Molecular e Bioinformática utilizadas para obter a sequência de ácidos nucleicos de uma amostra biológica. A utilização dessas técnicas vêm crescendo vertiginosamente desde a sua criação, quinze anos atrás, e se expande por várias áreas da ciência como saúde humana, agricultura e conservação da biodiversidade. Neste artigo mostramos as principais plataformas de NGS utilizadas atualmente e discutimos as principais contribuições da técnica, bem como as perspectivas do NGS para o futuro.

\section{Introdução}

O Sequenciamento de Nova Geração (NGS - sigla em inglês para Next Generation Sequencing ou na tradução "Sequenciamento de Próxima Geração") é o nome dado ao conjunto das mais modernas técnicas para a identificação das sequências de ácidos nucleicos (DNA e RNA) das mais variadas amostras biológicas, tais como plantas, animais e microrganismos [1]. São técnicas que se sobrepuseram ao modelo de Sanger [2] após o Projeto Genoma Humano e que surgiram da necessidade de se produzir sequenciamentos mais rápidos, econômicos e de qualidade [3].

O primeiro sequenciador de nova geração, o 454, lançado em 2005 (veja abaixo mais informações), já era capaz de sequenciar com uma capacidade 50x maior que o principal sequenciador de Sanger disponível na época e causou um certo alvoroço na comunidade científica $[3,4]$. Num primeiro momento as técnicas foram criticadas principalmente por produzirem sequências pequenas, entre 50 e 300 pares de bases, enquanto o método de Sanger produzia fragmentos na casa dos $750 \mathrm{pb}$ [3], mas o tempo mostrou que a técnica tinha muito potencial a entregar. Já nos primeiros trabalhos se sobressaíram características como o grande número de sequências produzidas, a quantidade de reações que podiam ser paralelizadas e a 
possibilidade de detecção direta das sequências, sem o auxílio de um gel de eletroforese [5].

Hoje, as técnicas disponíveis permitem o sequenciamento cada vez mais rápido e barato, como mostra uma estimativa do NIH, o Instituto Nacional de Saúde dos Estados Unidos (Figura 1). No começo do século XXI, o custo para sequenciar 1 milhão de pares de bases era de US $\$ 10 \mathrm{mi}$, enquanto nos dias de hoje, apenas 20 anos depois, está na casa de 1 centavo de dólar. É uma queda abrupta que permitiu a popularização da técnica e sua disseminação pelo mundo [6].

Com as constantes melhorias nas plataformas de sequenciamento, a bioinformática evoluiu em conjunto. A capacidade computacional disponível em 2005 era similar a dos celulares mais básicos hoje em dia e as cadeias computacionais envolvidas dentro do processo de sequenciamento precisaram e precisam constantemente se adaptar às novas ferramentas e facilidades desenvolvidas [7]. Neste artigo, mostraremos as principais plataformas de sequenciamento de nova geração existentes, o impacto que elas tiveram para a evolução do conhecimento e as perspectivas para o uso das tecnologias NGS.

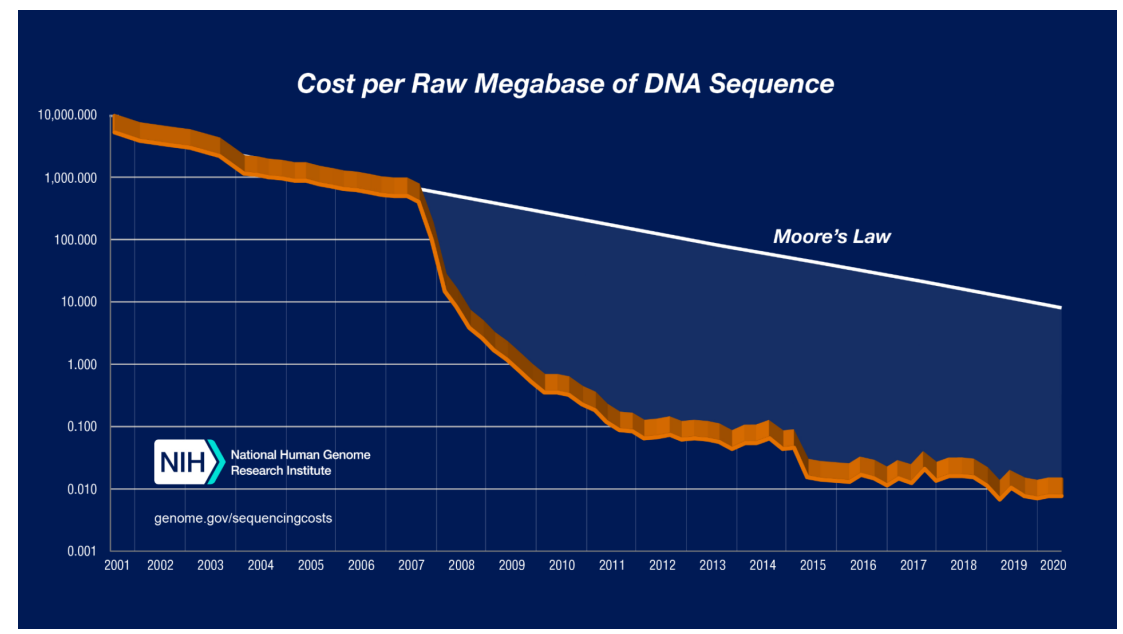

Figura 1. Custo para sequenciamento de um milhão de bases de DNA ao longo do tempo. Fonte: https://www.genome.gov/.

\section{Principais Plataformas de Sequenciamento}

\section{Pirosequenciamento 454}

Após o sucesso na utilização do sequenciamento automatizado usando o método Sanger pela plataforma ABI (Applied Biosciences), novas formas de sequenciamento classificados como segunda, terceira geração e quarta geração, foram desenvolvidos e aperfeiçoados ao longo dos anos. O primeiro método de sequenciamento de segunda geração lançado foi o 
pirosequenciamento, lançado pela plataforma 454 Life Sciences. Esse método, diferente de Sanger que utilizava a tecnologia com nucleotídeos marcados (dideoxinucleotídeos), utiliza a detecção de pirofosfato, um subproduto da incorporação de nucleotídeos, que ao serem incorporados no produto da reação (DNA de interesse), emitem uma luz que ao ser detectada permite que o fragmento sequenciado seja identificado [8], como demonstrado na figura 2.

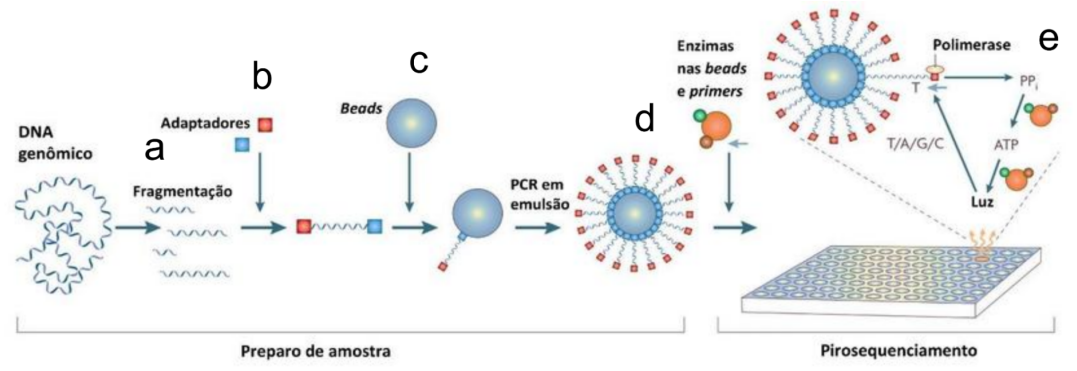

Figura 2. (a) O primeiro passo do pirosequenciamento é a fragmentação do DNA de interesse através do método shotgun (fragmentação do DNA em pequenos pedaços), posteriormente adicionando os chamados adaptadores (b), que se ligam às extremidades 5' e 3' dos fragmentos, e auxiliam o DNA fragmentado a se ligar nas beads magnéticas (esferas de metal com pequenas sequências de DNA complementares) (c). Essas beads serão "capturadas" uma a uma por gotículas de óleo, para realizar o próximo passo do pirosequenciamento, que é o $P C R$ em emulsão (d). O PCR em emulsão vai gerar micelas através da solução oleosa que essa técnica utiliza, gerando "microrreatores" para produção de novos fragmentos, e assim, ter fragmentos o suficiente para iniciar o processo de sequenciamento. As microesferas são capturadas individualmente nos poços do suporte de sequenciamento e, em seguida, são adicionados os reagentes para a reação de pirosequenciamento. À medida que o sinal de luz é emitido, é identificada a base que é incorporada em cada poço do sequenciamento (e). Fonte: adaptado de [9].

Essa tecnologia foi muito utilizada para sequenciamento de genomas de novo, que são genomas ainda não caracterizados. Essa técnica entrou em desuso próximo ao ano de 2013, com o surgimento das posteriores tecnologias de sequenciamentos.

\section{Ion Torrent}

O lon torrent é uma plataforma de sequenciamento considerado uma transição entre a segunda e a terceira geração de sequenciadores, que foi lançada no mercado no mês de fevereiro de 2010. Diferente do método utilizado no Sanger e Illumina (falaremos no próximo tópico), que utilizam nucleotídeos marcados com fluorocromos para detecção da fita sintetizada no sequenciamento, a tecnologia Ion utiliza a diferença de $\mathrm{pH}$, sendo um método conhecido como pHmetro que sequencia DNA [10].

O método consiste basicamente em "capturar" o DNA alvo em micropoços, fragmentar o DNA de interesse, ligar aos adaptadores e amplificar os fragmentos por PCR em emulsão. Os fragmentos resultantes são colocados em um chip com micropoços e os nucleotídeos são adicionados um a um por uma DNA polimerase. Quando o nucleotídeo é incorporado, uma molécula de $\mathrm{H}+$ é liberada, alterando o pH da solução. Uma espécie de "sensor de íons" é utilizado para detectar essa mudança na diferença de pH (figura 3). A 
intensidade da voltagem detectada pelo sensor é de acordo com a quantidade de nucleotídeos incorporados, ou seja, quanto mais nucleotídeos foram adicionados em sequência, maior será a diferença de pH. No caso de nenhum nucleotídeo ser adicionado, não haverá emissão de sinal no detector [10]. A vantagem dessa técnica está no não uso de nucleotídeos marcados, diferente das técnicas de Sanger e Illumina. Com isso, diminui o ruído de fluorescência que pode ser detectado no sistema. Contudo, esse método pode apresentar erros na inserção ou deleção de nucleotídeos em regiões de sequências repetitivas, podendo causar uma saturação no detector de $\mathrm{pH}$ do aparelho.

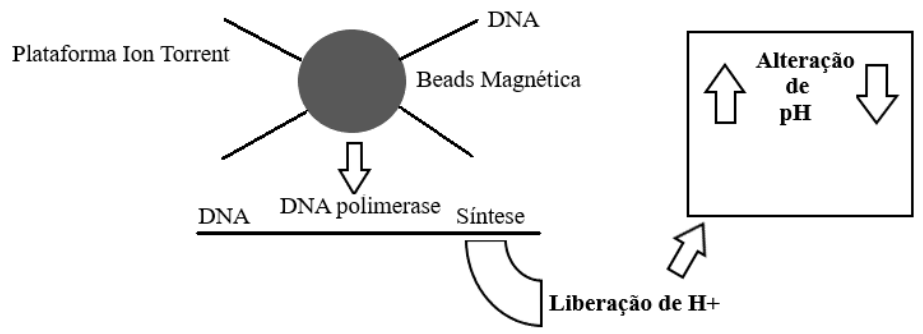

Figura 3. Imagem ilustrativa sobre o princípio da tecnologia utilizada nos sequenciadores da plataforma Ion Torrent. A liberação de uma molécula de $\mathrm{H}^{+}$durante a adição dos nucleotídeos altera o pH da solução, o que é detectado pelo sensor de íons do aparelho.

\section{Illumina}

A Illumina surgiu após aquisição da empresa Solexa, empresa criadora do método de amplificação em ponte (bridge amplification), método utilizado até os dias de hoje nos sequenciadores Illumina. Desde então, a Illumina vem crescendo no mercado e hoje é a maior plataforma de sequenciamento do mundo. E não é por acaso que a Illumina cresceu tanto. Isso está ligado a qualidade de sequenciamento e também nos diferentes kits e metodologias dispostas, facilitando assim o método para diferentes áreas de interesse como: diagnóstico molecular, oncologia, genética microbiana, genômica agrária e forense. Existem opções para sequenciar fragmentos menores de DNA até um genoma completo. Para sequenciamento de RNA, essa plataforma utiliza uma técnica baseada em cDNA (DNA complementar) através de um ensaio de transcrição reversa (conversão de moléculas de RNA para moléculas de DNA através de uma enzima transcriptase reversa), e assim, sequenciar o RNA total de uma amostra, o mRNA (RNA mensageiro), pequenos RNAs ou até mesmo genes específicos [9].

A metodologia utiliza o sequenciamento por síntese: utilização de uma DNA polimerase com nucleotídeos marcados com fluorocromos, os chamados dideoxinucleotídeos. O método consiste na fragmentação do DNA para a elaboração da biblioteca de DNA em tamanhos compatíveis com os que a plataforma exige. Após isso, são adicionados os adaptadores nos fragmentos, que se ligam nas extremidades dos fragmentos e ao suporte utilizado no 
sequenciamento Illumina chamado flow cell. Os adaptadores ligam-se a sequências complementares no flow cell em formato de ferradura " $\cap$ ", amplificando os fragmentos através de pontes de amplificação (amplificação por ponte, figura 4). Após a formação dos chamados "clusters", a DNA polimerase utiliza os adaptadores como primer, se liga e estende adicionando nucleotídeos marcados, que emitem uma fluorescência e o equipamento reconhece o nucleotídeo, e assim, vai se formando a sequência do fragmento que está sendo sequenciado $[9,11]$.

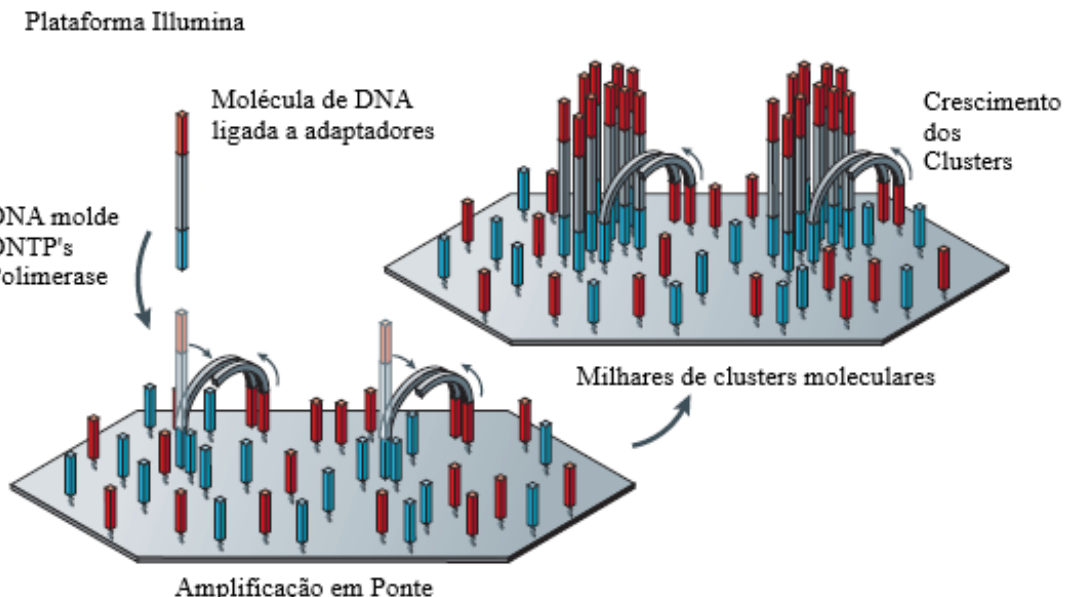

Figura 4. Amplificação em ponte, método utilizado nos equipamentos da tecnologia Illumina de sequenciamento. Fonte: adaptado de [12].

\section{PacBio}

Lançado no ano de 2009 pela Pacific Biosciences, PacBio é considerado como parte da terceira geração de sequenciadores de DNA. Conhecido por um processo de sigla SMRT (Single-Molecule Real Time), PacBio revolucionou o método de sequenciamento pelo modo de operação em tempo real (observação em tempo real dos nucleotídeos adicionados no fragmento presente no sequenciamento), método que até então nenhum tipo de sequenciador era capaz de realizar. O PacBio se baseia em enzimas DNA polimerase intrínsecas, fixadas em um suporte e que catalisam a reação com a adição de nucleotídeos complementares à fita molde (figura 5).

Juntamente com a DNA polimerase fixada ao suporte, também há um detector ZMW (Zero-Mode Waveguide Detector). Nesse processo, ocorre a utilização de fluorescência para detecção dos nucleotídeos que estão sendo adicionados no momento da reação. À medida que a enzima DNA polimerase adiciona nucleotídeos complementares a fita única do DNA molde, esses nucleotídeos liberam uma fluorescência que é detectado pelo detector ZMW, que está também fixado ao suporte de vidro do sequenciador. Nesse processo, é utilizada uma DNA polimerase modificada que tem alta afinidade por nucleotídeos fosfoligados. Esses nucleotídeos também são modificados pois possuem seis grupos fosfatos, na qual um deles é ligado ao fluoróforo $[9,12]$. 


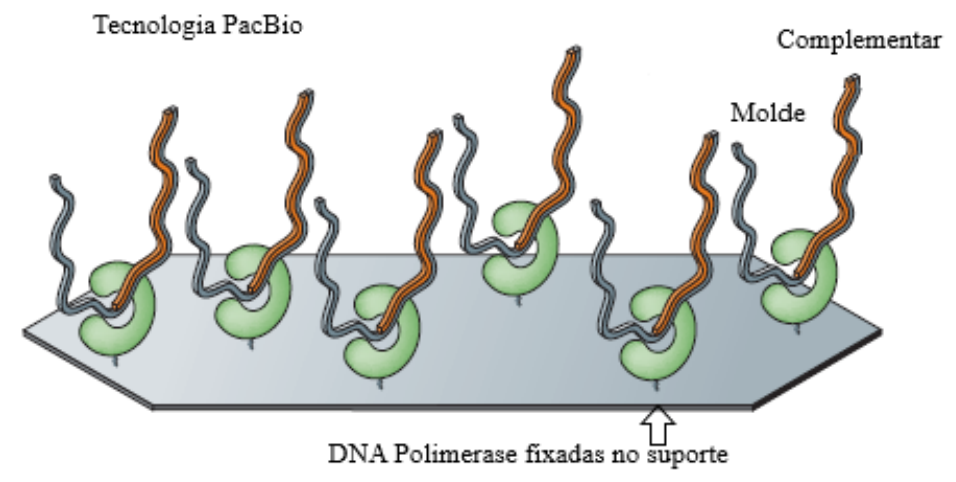

Figura 5. Figura demonstrando o princípio da tecnologia PacBio de sequenciamento. Podemos observar as polimerases fixadas em um suporte físico recebendo o DNA molde adicionando o trecho complementar com os nucleotídeos fosfoligados. Fonte: adaptado de [12].

\section{Nanopore}

Seguindo na linha de inovação dos processos de sequenciamento tanto para otimizar o tempo de processamento e uma maior quantidade de dados, Oxford Nanopore Technologies lançou em 2012 a tecnologia Nanopore, pertencente a terceira geração de sequenciadores. Diferente de outros métodos anteriormente lançados, este não utiliza diferença de pH para detecção de nucleotídeos, tão pouco uso de nucleotídeos marcados ou métodos de amplificação em ponte. O método Nanopore, apesar de mais simples, é um poderoso método de pequena e larga escala. A Oxford Nanopore lançou dois tipos de sequenciadores para revolucionar a arte do sequenciamento. O MinION é um dispositivo portátil, do tamanho de um pendrive, mas extremamente poderoso quando o assunto é sequenciamento de genomas. Ele é capaz de sequenciar até 1Gb de DNA. Já o segundo sequenciador que foi lançado, o GridION, que possui tamanho mais avantajado, é voltado para o sequenciamento de genes em larga escala [13].

A tecnologia Nanopore se baseia no cálculo da diferença de potencial e a corrente iônica que cada nucleotídeo emite ao passar pelo poro da enzima. $O$ poro biológico usado é de uma $\alpha$-hemolisina modificada, contendo uma ciclodextrina localizada na região barril da $\alpha$-hemolisina, que "prende" os nucleotídeos no poro por pelo menos $10 \mathrm{~ms}$ (milissegundos), para que haja tempo hábil para a detecção dos nucleotídeos (figura 6 a, b). Todo esse processo ocorre sob supervisão de uma DNA polimerase, que controla a velocidade da reação, que pode ser modificada à medida que é alterada a corrente elétrica aplicada no sistema (figura 6a) [14,15]. 


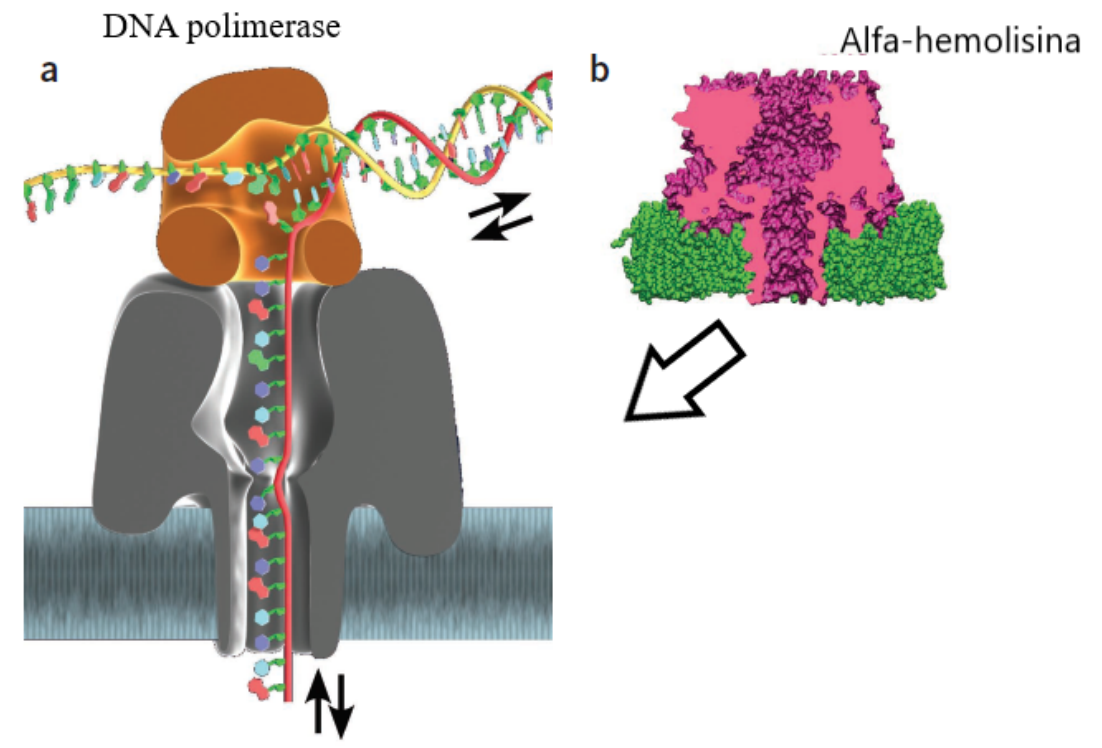

Figura 6. Imagem ilustrando a tecnologia Nanopore de sequenciamento. Observamos a enzima a-hemolisina com a "supervisão" de uma DNA polimerase que auxilia no controle da velocidade da reação. Notem que o DNA que está sendo sequenciado passa por dentro do poro da enzima, e a velocidade com que os nucleotídeos passam por esse poro é medida pelo aparelho, e assim, é identificado qual nucleotídeo foi incorporado. Fonte: adaptado de [15].

\section{Contribuições do NGS}

O output dos sequenciadores de nova geração consiste primariamente em um arquivo de extensão . fastq ou .fast5. Esse arquivo contém as sequências identificadas pela máquina e informações sobre elas, como a qualidade da identificação de cada base. Entretanto, esse arquivo sozinho diz muito pouco sobre as amostras sequenciadas, pois precisa ser processado adequadamente para que demonstre informações de forma gráfica e passivel de interpretação. Dessa forma, um dos primeiros grandes feitos do NGS foi promover o avanço dos programas e scripts utilizados para processar esses dados gerados. Iniciativas como o Scaffold Builder para montagens de genomas [16], dada2 para a análise de amplicons microbianos [17] e o Canu para trabalho com reads longos e curtos ao mesmo tempo (como no caso da utilização de duas plataformas de sequenciamento diferentes para a mesma amostra) [18] são exemplos de tecnologias que foram desenvolvidas para resolver problemas que não existiam antes do advento do NGS e melhorar o processamento de dados.

A combinação de melhores plataformas e ferramentas computacionais mais potentes permitiu grandes avanços no estudo dos mais diversos temas. Estudos focados tanto em fechamento de genomas, sequenciamento e anotação de transcriptomas, metilações, amplicons e muitas outras abordagens puderam ser feitos de maneira mais rápida e prática numa escala até então impraticável. O número de artigos que mencionam o termo "NGS" em algum ponto do seu título ou do seu resumo passou dos 3.300 
artigos em 2020, o que demonstra um crescimento exponencial desde 2005. Isso mostra o quanto a técnica tem se popularizado e ganhado força.

Um dos avanços mais significativos proporcionados pelo NGS tem sido na luta contra os cânceres. Diversas patologias e padrões genéticos têm sido encontrados como genes associados a diversos tipos de tumores, fatores hereditários e aberrações cromossômicas [19]. Um ótimo exemplo de repercussão mundial foi o caso da atriz Angelina Jolie, que descobriu a presença de mutações no seu gene $B R C A l$, uma condição fortemente ligada ao câncer de mama [20]. Ainda que a associação desse gene com o tumor seja anterior ao NGS [21,22], somente com as novas técnicas de sequenciamento é que se tornou acessível se sequenciar um genoma humano de maneira comercial a fim de identificar possíveis mutações ligadas não só a câncer, mas também a diversos outros problemas de saúde.

Outra área que tem se beneficiado muito do NGS é a microbiologia. O estudo de microbiomas, o conjunto dos microrganismos de um determinado ambiente, avançou largamente devido à facilidade de se acessar o conteúdo microbiano. Também ajuda nisso o fato de o NGS ser completamente independente do cultivo, permitindo a identificação de microrganismos não cultiváveis, que representam mais de $90 \%$ da diversidade microbiana conhecida [23]. O conhecimento hoje já relaciona a microbiota com doenças e comorbidades humanas como Alzheimer [24], parto prematuro [25,26] e autismo [27], tratando o ser humano não mais como um organismo, mas como um "superorganismo" composto de células humanas e microbianas [28]. O mesmo também é válido para relações dos microrganismos com plantas [29] e com animais [30].

A montagem e anotação de genomas também foi extremamente beneficiada pelo NGS. O processo de sequenciamento era extremamente lento pelo método de Sanger, tendo o rascunho do genoma humano demorado mais de dez anos para ser finalizado [31,32]. Hoje, com o NGS e as novas e modernas técnicas computacionais, algumas empresas oferecem o serviço de sequenciamento completo em uma semana [33]. O reflexo disso se dá no aumento massivo na quantidade de genomas completos depositados em bancos de dados públicos, como o Genbank, do NCBI, que conta com mais de 25 mil genomas sequenciados, a grande maioria depositados com o auxílio do NGS. O mesmo acontece com os transcriptomas, o conjunto de RNAs transcritos por um organismo. Além disso, o sequenciamento NGS permitiu o avanço no conhecimento sobre os genes expressos em determinadas condições por diferentes espécies através do sequenciamento do cDNA [34].

O conhecimento adquirido pelo sequenciamento em massa de genomas e transcriptomas traz grandes benefícios no longo prazo, principalmente quando associado a estudos de filogenia. Estudos nesse sentido nos permitem entender a evolução molecular das espécies e como elas se relacionam tanto entre si quanto com a história da humanidade [35]. Também é possível prospectar genes de interesse, como proteínas de 
resistência ao frio para possível inserção em culturas agrícolas [36,37], bem como rastrear organismos de acordo com sua origem. Este último exemplo inclui estudos recentes sobre rastreabilidade genética de drogas ilícitas $[38,39]$ e também da identificação e rastreio das novas variantes do SARSCoV-2, o coronavírus responsável pela pandemia global de COVID-19 [40,41].

\section{Conclusões e Perspectivas}

O sequenciamento de nova geração é uma ferramenta de grande poder e que permitiu e tem permitido enormes avanços no conhecimento. $O$ barateamento e a facilidade de uso das diferentes plataformas tendem a ampliar cada vez mais seu uso e as suas aplicações. Novas plataformas que permitem o sequenciamento fora do laboratório (como no caso do MinION) ainda podem levar o NGS a lugares inóspitos e ainda inexplorados, provendo as ferramentas necessárias para conhecer toda uma biodiversidade até então desconhecida [42].

Os avanços esperados em saúde humana também são grandes. Num contexto em que o termo farmacogenômica ganha cada vez mais destaque, o NGS se destaca como uma ferramenta essencial para mapear as individualidades genéticas dos indivíduos e a melhora nos tratamentos personalizados [43]. Da mesma forma, uma melhor gestão de epidemias e pandemias pode ser obtida por meio do uso de ferramentas de sequenciamento rápido, que permitem o mapeamento de novas variantes e da disseminação das doenças quase que em tempo real. Muito disso vem sendo mostrado na pandemia da COVID-19, mas também se mostrou eficiente em epidemias anteriores como SARS, MERS e ebola $[44,45]$.

Além de tudo, o NGS pode estar mudando a forma como comemos. As revoluções na agricultura e na pecuária passam muito pelo quanto os avanços da biologia molecular (e inclua-se aqui largamente o NGS) das últimas décadas. Alimentos transgênicos hoje são uma realidade palpável e o uso dessas técnicas em animais de produção também começa a gerar frutos $[30,46]$.

Tudo à nossa volta parece estar ligado ao NGS, e de certa forma está. Se considerarmos que tudo que é vivo apresenta material genético, tudo pode ser sequenciado e gerar conhecimento. Não sabemos ao certo para onde esse conhecimento convergirá, mas as perspectivas são de que cada vez mais as letras $A, T, C$ e $G$ passem a dizer muito mais sobre o mundo à nossa volta do que os nossos olhos são capazes de enxergar.

\section{Referências}

1. Varstation. NGS: O que é Sequenciamento de Nova Geração? [Internet]. Varsomics. 2019 [cited 2021 May 22]. Available from: 
https://blog.varsomics.com/o-que-e-sequenciamento-de-nova-geracaongs/

2. Stussi F, Brito F. Sequenciamento de primeira geração: método de Sanger [Internet]. Rev. Bras. Bioinformática. 2021 [cited 2021 May 22]. Available from: https://bioinfo.com.br/sequenciamento-de-primeira-geracao-metodo-desanger/

3. Schuster SC. Next-generation sequencing transforms today's biology. Nat Methods. 2007;5:16.

4. Neoprospecta. Plataformas de sequenciamento de DNA [Internet]. Blog Neoprospecta. 2016 [cited 2021 May 22]. Available from:

https://blog.neoprospecta.com/plataformas-sequenciamento-dna/

5. van Dijk EL, Auger H, Jaszczyszyn Y, Thermes C. Ten years of next-generation sequencing technology. Trends Genet. 2014;30:418-26.

6. $\mathrm{NIH}$. The Cost of Sequencing a Human Genome [Internet]. Genome.gov. 2020 [cited 2021 May 22]. Available from: https://www.genome.gov/aboutgenomics/fact-sheets/Sequencing-Human-Genome-cost

7. Jünemann S, Kleinbölting N, Jaenicke S, Henke C, Hassa J, Nelkner J, et al. Bioinformatics for NGS-based metagenomics and the application to biogas research. J Biotechnol. 2017;261:10-23.

8. Ronaghi M, Uhlen M, Nyrén P. A Sequencing Method Based on Real-Time Pyrophosphate. Science. 1998;281:363, 365.

9. Turchetto-Zolet A, Turchetto C, Guzman F, Silva GA, Sperb Ludwig F, Vetö N. Capítulo 8 Polimorfismo de Nucleotídeo único (SNP): metodologias de identificação, análise e aplicações. 2017.

10. Rusk N. Torrents of sequence. Nat Methods. 2011;8:44-44.

11. Liu L, Li Y, Li S, Hu N, He Y, Pong R, et al. Comparison of Next-Generation Sequencing Systems. J Biomed Biotechnol. 2012;2012:1-11.

12. Metzker ML. Sequencing technologies - the next generation. Nat Rev Genet. 2010;11:31-46.

13. Eisenstein M. Oxford Nanopore announcement sets sequencing sector abuzz. Nat Biotechnol. 2012;30:295-6.

14. Laszlo AH, Derrington IM, Ross BC, Brinkerhoff H, Adey A, Nova IC, et al. Decoding long nanopore sequencing reads of natural DNA. Nat Biotechnol. 2014;32:829-33. 
15. Schneider GF, Dekker C. DNA sequencing with nanopores. Nat Biotechnol. 2012;30:326-8.

16. Silva GG, Dutilh BE, Matthews TD, Elkins K, Schmieder R, Dinsdale EA, et al. Combining de novo and reference-guided assembly with scaffold_builder. Source Code Biol Med. 2013;8:23.

17. Callahan BJ, McMurdie PJ, Rosen MJ, Han AW, Johnson AJA, Holmes SP. DADA2: High-resolution sample inference from Illumina amplicon data. Nat Methods. 2016;13:581-3.

18. Koren S, Walenz BP, Berlin K, Miller JR, Bergman NH, Phillippy AM. Canu: scalable and accurate long-read assembly via adaptive k-mer weighting and repeat separation. Genome Res. 2017;27:722-36.

19. Stratton MR, Campbell PJ, Futreal PA. The cancer genome. Nature. 2009;458:719-24

20. Grady D, Parker-Pope T, Belluck P. Jolie's Disclosure of Preventive Mastectomy Highlights Dilemma. N Y Times [Internet]. 2013 May 14 [cited 2021 May 24]; Available from:

https://www.nytimes.com/2013/05/15/health/angelina-jolies-disclosurehighlights-a-breast-cancer-dilemma.html

21. Amendola LCB, Vieira R. A contribuição dos genes BRCA na predisposição hereditária ao câncer de mama. Rev Bras Cancerol. 2005;51:6.

22. Robson M, Gilewski T, Haas B, Levin D, Borgen P, Rajan P, et al. BRCAassociated breast cancer in young women. J Clin Oncol. Wolters Kluwer; 1998;16:1642-9.

23. Hasman H, Saputra D, Sicheritz-Ponten T, Lund O, Svendsen CA, FrimodtMøller N, et al. Rapid Whole-Genome Sequencing for Detection and Characterization of Microorganisms Directly from Clinical Samples. J Clin Microbiol. 2014;52:139-46.

24. Itzhaki RF, Lathe R, Balin BJ, Ball MJ, Bearer EL, Braak $H$, et al. Microbes and Alzheimer's Disease. J Alzheimers Dis JAD. 2016;51:979-84.

25. Romero R, Hassan SS, Gajer P, Tarca AL, Fadrosh DW, Bieda J, et al. The vaginal microbiota of pregnant women who subsequently have spontaneous preterm labor and delivery and those with a normal delivery at term. Microbiome. 2014;2:18.

26. de Freitas AS, Dobbler PCT, Mai V, Procianoy RS, Silveira RC, Corso AL, et al. Defining microbial biomarkers for risk of preterm labor. Braz J Microbiol 
[Internet]. 2019 [cited 2019 Jul 23]; Available from:

http://link.springer.com/10.1007/s42770-019-00118-x

27. Johnson S, Hollis C, Kochhar P, Hennessy E, Wolke D, Marlow N. Autism Spectrum Disorders in Extremely Preterm Children. J Pediatr. 2010;156:525531.e2.

28. Sleator RD. The human superorganism - Of microbes and men. Med Hypotheses. 2010;74:214-5.

29. Turner TR, James EK, Poole PS. The plant microbiome. Genome Biol. 2013;14:209.

30. de Freitas AS, de David DB, Takagaki BM, Roesch LFW. Microbial patterns in rumen are associated with gain of weight in beef cattle. Antonie Van Leeuwenhoek. 2020;113:1299-312.

31. Venter JC, Adams MD, Myers EW, Li PW, Mural RJ, Sutton GG, et al. The Sequence of the Human Genome. Science. American Association for the Advancement of Science; 2001;291:1304-51.

32. Lander ES, Linton LM, Birren B, Nusbaum C, Zody MC, Baldwin J, et al. Initial sequencing and analysis of the human genome. Nature. Nature Publishing Group; 2001;409:860-921.

33. The Sequencing Center. How long does genome sequencing take? [Internet]. 2020 [cited 2021 May 25]. Available from: https://thesequencingcenter.com/knowledge-base/how-long-doesgenome-sequencing-take/

34. Clementi M, Menzo S, Bagnarelli P, Manzin A, Valenza A, Varaldo PE. Quantitative PCR and RT-PCR in virology. Genome Res. 1993;2:191-6.

35. Wang H, Xu X, Vieira FG, Xiao Y, Li Z, Wang J, et al. The Power of Inbreeding: NGS-Based GWAS of Rice Reveals Convergent Evolution during Rice Domestication. Mol Plant. 2016;9:975-85.

36. Carvalho EL, Maciel LF, Macedo PE, Dezordi FZ, Abreu MET, Victória F de C, et al. De novo Assembly and Annotation of the Antarctic Alga Prasiola crispa Transcriptome. Front Mol Biosci [Internet]. Frontiers; 2018 [cited 2021 May 25];4. Available from:

https://www.frontiersin.org/articles/10.3389/fmolb.2017.00089/full

37. Mizrahi T, Heller J, Goldenberg S, Arad Z. Heat shock protein expression in relation to reproductive cycle in land snails: Implications for survival. Comp Biochem Physiol A Mol Integr Physiol. 2011;160:149-55. 
38. Freitas AS, Anunciação RR, D'Oliveira-Matielo CB, Stefenon VM. Chloroplast DNA: A Promising Source of Information for Plant Phylogeny and Traceability. 2018;1:4.

39. Matielo CBD, Lemos RPM, Sarzi DS, Machado L de O, Beise DC, Dobbler PCT, et al. Whole Plastome Sequences of Two Drug-Type Cannabis: Insights Into the Use of Plastid in Forensic Analyses. J Forensic Sci. 2020;65:259-65.

40. Resende PC, Naveca FG, Lins RD, Dezordi FZ, Ferraz MVF, Moreira EG, et al. The ongoing evolution of variants of concern and interest of SARS-CoV-2 in Brazil revealed by convergent indels in the amino $(\mathrm{N})$-terminal domain of the Spike protein. medRxiv. Cold Spring Harbor Laboratory Press;

2021;2021.03.19.21253946.

41. Motayo BO, Oluwasemowo OO, Olusola BA, Akinduti PA, Arege OT, Obafemi YD, et al. Evolution and genetic diversity of SARS-CoV-2 in Africa using whole genome sequences. Int J Infect Dis IJID Off Publ Int Soc Infect Dis. 2021;103:2827.

42. Dini-Andreote F, van Elsas JD, Olff H, Salles JF. Dispersal-competition tradeoff in microbiomes in the quest for land colonization. Sci Rep. Nature Publishing Group; 2018;8:9451.

43. Rogers SL, Patrinos GP, Mitropoulou C, Formea CM, Jones JS, Brown BG. Conference report: inaugural Pharmacogenomics Access and Reimbursement Symposium. Pharmacogenomics [Internet]. Future Medicine; 2021 [cited 2021 May 29]; Available from: https://www.futuremedicine.com/doi/10.2217/pgs2021-0016

44. Naveca FG, Nascimento V, de Souza VC, Corado A de L, Nascimento F, Silva $G$, et al. COVID-19 in Amazonas, Brazil, was driven by the persistence of endemic lineages and P.1 emergence. Nat Med [Internet]. 2021 [cited 2021 May 29]; Available from: http://www.nature.com/articles/s41591-021-01378-7

45. Van Puyvelde S, Argimon S. Sequencing in the time of Ebola. Nat Rev Microbiol. Nature Publishing Group; 2019;17:5-5.

46. Van Emon JM. The Omics Revolution in Agricultural Research. J Agric Food Chem. 2016;64:36-44. 